\title{
Gestational Age Conformity between New Ballard Score and Last Menstrual Period in Newborn with Respiratory Distress Syndrome
}

\author{
Wulan Dwi Sakinah, ${ }^{1}$ Aris Primadi, ${ }^{2}$ Ihrul Prianza Prajitno ${ }^{3}$ \\ ${ }^{1}$ Faculty of Medicine Universitas Padjadjaran, ${ }^{2}$ Department of Child Health Faculty of Medicine, \\ Universitas Padjadjaran/Dr. Hasan Sadikin General Hospital Bandung, ${ }^{3}$ Department of Anatomy \\ and Cellular Biology Faculty of Medicine Universitas Padjadjaran
}

\begin{abstract}
Background: Gestational age is required to determine diagnosis and optimal management of newborns. The gold standard for gestational age determination is the first day of last menstrual period (LMP). However, not all mothers remember their LMP. Another method for gestational age determination after birth is the New Ballard Score (NBS). This method measures gestational age using two main components, namely neorumuscular and physical maturity. In premature infants, surfactant deficiency leads to hypoxia which eventually leads to neuromuscular disorders. This situation may cause younger gestational age estimation when using NBS. The objective of this study was to analyze the conformity between NBS and LMP in determining gestational age in newborns with respiratory distress syndrome (RDS).

Methods: A cross-sectional study was conducted on 35 newborns with RDS that were recorded in 2012 database in Dr. Hasan Sadikin General Hospital Bandung. Data on the date of birth, LMP, NBS soon after birth, sex, birth weight, type of delivery and diagnosis were collected and analyzed statistically using Wilcoxon test.

Results: The study showed that there was a significant difference $(p<0.05)$ between gestational age determination done using NBS soon after birth and LMP in newborns with RDS.

Conclusions: Gestational age determination based on NBS soon after birth does not conform the LMP in newborns with RDS. [AM].2016;3(3):401-4]
\end{abstract}

Keywords: Gestational age, last menstrual period, new Ballard score, respiratory distress syndrome

\section{Introduction}

Birth weight and gestational age have been known to be the primary determinants of neonatal morbidity and mortality. ${ }^{1}$ Gestational age is required to determine diagnosis and optimal management of the newborns. ${ }^{2}$ The Gold standard for gestational age assessment is the first day of last menstrual period (LMP). . $^{3-}$

${ }^{5}$ However, not all mothers know exactly their LMP. Thus, another method is required to assess the gestational age to be used if the LMP is unknown or doubtful. Another methods for gestational age determination of newborns are New Ballard Score (NBS) and Ballard score. In a previous study, it is suggested that NBS ( $\mathrm{r}=0.97)$ has a strong correlation with LMP than Ballard score ( $r=0.95)$, and NBS was more accurate and had a higher association coefficient $(\mathrm{k}=0.85)$ when compared to LMP in identifying premature babies, more than the Ballard score $(\mathrm{k}=0.82) .{ }^{3}$ The assessment of the gestational age based on NBS is obtained from scoring of both neuromuscular and physical maturity in newborns. ${ }^{6}$

The policy of Dr. Hasan Sadikin General Hospital Bandung requires that the five priority areas to be carefully recorded, including thesmanagement of Respiratory Distress Syndrome (RDS). Surfactant deficiency is the primary cause of prematurity in in RDS. 1,7,8 This circumstance leads to hypoxia which affects neuromuscular conditions which relates to the fact that one of the aspects assessed in NBS is the neuromuscular maturity. The gestational age determination of newborns with RDS when performed using NBS, is lower than that of the LMP. ${ }^{2}$ The objective of this study was to analyze the conformity of gestational age determination between NBS and LMP in newborns with RDS.

Correspondence: Wulan Dwi Sakinah, Faculty of Medicine, Universitas Padjadjaran, Jalan Raya Bandung-Sumedang Km.21, Jatinangor, Sumedang, Indonesia, Phone: +62 85353060379 Email: wulan.dwie21@gmail.com 


\section{Methods}

This was a cross-sectional study. Samples were taken from the 2012 database of newborns at the Division of Neonatology, Department of Child Health, Dr. Hasan Sadikin General Hospital, Bandung. This study was conducted after obtaining approval from the Health Research Ethics Committee of the Faculty of Medicine, Universitas Padjadjaran/Dr. Hasan Sadikin General Hospital, Bandung.

The minimum samples size required for 95\% confident interval (CI) and 90\% power test was 35 subjects. The inclusion criterion was newborns with RDS. Data on date of birth, LMP, NBS that obtained soon after birth, birth weight, type of delivery, and diagnosis were collected from the database. Newborns with marked congenital anomaly and incomplete data, with no LMP or NBS soon after birth data, were excluded from this study. The collected data were analyzed statistically using the nonparametric Wilcoxon test.

\section{Results}

From 68 newborns with RDS, only 38 newborns were included in this study. Of the 38 newborns included in this study, most of them were born with low birth weight and through spontaneous delivery (Table 1).

In this study, the subjects were not only diagnosed with RDS but were also diagnosed according to the complications they had, such as asphyxia, sepsis, and both of asphyxia and sepsis. Most of the subjects were diagnosed with RDS that was accompanied with asphyxia with a different gestational age determination using NBS and LMP (Table 2).
Table 1 Characteristics of Newborn with Respiratory Distress Syndrome

\begin{tabular}{lc}
\hline \multicolumn{1}{c}{ Characteristics } & $\mathbf{n = 3 8}$ \\
\hline Sex & 22 \\
Male & 16 \\
Female & \\
Birth Weight & 1 \\
NBW & 18 \\
LBW & 15 \\
VLBW & 4 \\
ELBW & \\
Delivery & 27 \\
Spontaneous & 8 \\
Caesarian section & 3 \\
Vacuum extraction & \\
\hline
\end{tabular}

Note: NBW=Normal birth weight; LBW=Low birth weight; VLBW=Very low birth weight; ELBW=Extremely low birth weight

According to NBS, all subjects were preterms, while LMP showed that 35 subjects were preterms and 3 subjects were full terms. The analysis using the Wilcoxon test confirmed that there was a significant difference $(p<0.05)$ between the gestational age based on LMP and NBS in newborns with RDS (Table 3).

\section{Discussions}

According to Engle ${ }^{7}$ and Liu et al. ${ }^{8}$, RDS is one of the most common causes of neonatal respiratory failure and neonatal death. This

Table 2 Gestational Age based on Clinical Diagnosis

\begin{tabular}{lccc}
\hline & n(38) & $\begin{array}{c}\text { Gestational age based on } \\
\text { LMP (wk) }\end{array}$ & $\begin{array}{c}\text { Gestational age based } \\
\text { on NBS (wk) }\end{array}$ \\
\hline $\begin{array}{l}\text { RDS } \\
\text { Median (min-max) } \\
\text { RDS with Asphyxia }\end{array}$ & 6 & $33(31-34)$ & $32.5(32-34)$ \\
$\begin{array}{l}\text { Median (min-max) } \\
\text { RDS with Sepsis }\end{array}$ & 23 & $31(23-40)$ & $30(26-36)$ \\
$\begin{array}{l}\text { Median (min-max) } \\
\text { RDS with Asphyxia \& Sepsis }\end{array}$ & 1 & 30 & 30 \\
Median (min-max) & 8 & $32.5(29-35)$ & $32.5(28-36)$ \\
\hline Note: LMP=first day of Last Menstrual Period; NBS=New Ballard Score; RDS=Respiratory Distress Syndrome
\end{tabular}

Note: LMP=first day of Last Menstrual Period; NBS=New Ballard Score; RDS=Respiratory Distress Syndrome 
Wulan Dwi Sakinah, Aris Primadi, Ihrul Prianza Prajitno: Gestational Age Conformity between New Ballard 403 Score and Last Menstrual Period in Newborn with Respiratory Distress Syndrome

Table 3 Comparisons of Gestational Age between LMP and NBS in Newborns with RDS

\begin{tabular}{lccc}
\hline \multicolumn{1}{c}{ Classification } & $\begin{array}{c}\text { LMP } \\
(\mathbf{n = 3 8})\end{array}$ & $\begin{array}{c}\text { NBS } \\
(\mathbf{n = 3 8})\end{array}$ & $\mathbf{p}$ \\
\hline Term & 3 & 0 & 0.038 \\
Preterm & 35 & 38 & \\
Median (min-max) & $32(23-40)$ & $32(26-36)$ & \\
\hline
\end{tabular}

study discovered that most of the subjects were male infants with low birth weight. This result was similar to a previous study conducted by Roth-Kleiner et al. ${ }^{9}$ and a theory stated by Kliegman et al. ${ }^{1}$ that the main cause of RDS is prematurity and its risk factors aremale gender, low birth weight, and caesarean section.

According to Limawal et $\mathrm{al}^{3}{ }^{3}$ there was a strong correlation between gestational age determination by LMP and New Ballard score $(r=0.97)$ for healthy infants, including preterm, full-term and post-term infants. The NBS is more accurate and has a higher association coefficient $(\mathrm{k}=0.85)$ than the Ballard score $(\mathrm{k}=0.82)$, when associated to LMP, in identifying premature baby. According to Ballard et al. ${ }^{6}$ the NBS is a valid and accurate gestational assessment tool for extremely premature infants and remains valid for the entire newborn infant population. According to Sashidaran et al. ${ }^{5} \mathrm{NBS}$ in $5^{\text {th }}$ to $7^{\text {th }}$ day provides better results than NBS 24 hours after birth.

In this study, the NBS was obtained only soon after birth and the results showed that of the 38 subjects, 35 subjects were preterms according to the first day of LMP, while according to the NBS after birth, subjects were preterms. There was no conformity of gestational age determination between the NBS after birth and LMP in newborns with RDS $(p<0.05)$.

The results of this study are similar to a study conducted by Mujawaretal. ${ }^{2}$ which stated that in full-term newborns with asphyxia and without asphyxia, there were gestational age differences, when determination was performed using LMP and NBS on the first and second day after birth. In that study, there were 62 subjects, with 32 subjects suffered from asphyxia and 30 subjects without asphyxia. These subjects had their gestational age calculated using the NBS from the $1^{\text {st }}$ to $7^{\text {th }}$ day after birth, which was then adjusted to LMP. The results showed that the NBS to LMP conformity in newborns with asphyxia was lower than in newborns without asphyxia with Zk-s=3.681 $(\mathrm{p}<0.001){ }^{2}$
The condition of a newborn is greatly affected by RDS. Surfactant deficiency is the primary cause of RDS. ${ }^{1,7,8}$ Lack of surfactant causes high alveolar surface tension and decreased compliant. ${ }^{1,10}$ This condition leads to failure to attain an adequate functional residual capacity (FRC) and alveolar atelectasis. ${ }^{1,10}$ In RDS, lung cell inflammation also contributes to respiratory failure. ${ }^{11}$ This circumstance triggers hypoxia and hypercapnia.1,10 Hypoxia might cause anaerobic metabolic processes that ended up in impaired muscle contractility, making the infant experience hypotonia. ${ }^{2}$ Muscle contractility is affected by the availability of adenosine 5-triphosphate (ATP). Limited oxygen in the body might lead to derivation of ATP syinthesis. ${ }^{2}$ This condition influences the scoring of neuromuscular maturity in NBS; thus, the gestational age determination based on NBS in neonatal with RDS is lower than the gestational age determined using LMP.

There were several limitations in this study such as NBS was only obtained soon after birth and was not repeated, subjects were not only diagnosed with RDS but also with accompanying asphyxia, sepsis, or both of asphyxia and sepsis, and possible bias of LMP due to the fact that the data were secondary data (only from a database).

It is concluded that there is no conformity between NBS soon after birth and LMP in gestational age determination in newborns with RDS. Further study to determine the conformity and appropriate time to assess the gestational age using NBS in newborn with RDS without asphyxia or sepsis is needed. This study may gain more advantages if it is done in cohort to minimize recall bias of LMP.

\section{References}

1. Kliegman RM, Stanton BF, Schor NF, III JWSG, Behrman RE, editors. Nelson texbook of pediatrics. 19th ed. Philadelphia: Elsevier Saunders; 2011. p. 581-90.

2. Mujawar IJ, Somasetia DH, Effendi SH. Kesesuaian skorNew Ballard terhadap hari 
pertama haid terakhir ibu pada bayi cukup bulan yang lahir asfiksia dan tidak asfiksia. J Indon Med Assoc. 2011;61(10):400-4.

3. Limawal F, Madjid DA, Daud D. The accuracy of determining newborn's maturity between New Ballard's score, Ballard's score, and first day of last menstrual period. Paediatr Indones. 2008;48(2):5963.

4. Rosenberg RE, Ahmed AS, Ahmed S, Saha SK, Chowdhury MA, Black RE, et al. Determining gestational age in a low-resource setting: validity of last menstrual period. J Health Popul Nutr. 2009;27(3):332-8.

5. Sashidaran K, Dutta S, Narang A, Boyd E. Validity of new ballard score until 7th day of postnatal life in moderately preterm neonates. Arch Dis Chil Fetal Neonatal Ed. 2009;94:39-44.

6. Ballard JL, Khoury JC, Wedig K, Wang L, Eilers-Walsman B, Lipp R. New Ballard Score, expanded to include extremely premature infants. J Pediatr. 1991;119(3):417-23.

7. Engle WA. Surfactant-replacement therapy for respiratory distress in the preterm and term neonate. Pediatrics. 2008;121(2):419-32.

8. Liu J, Shi Y, Dong JY, Zheng T, Li JY, Lu LL, et al. Clinical characteristics, diagnosis and management of respiratory distress syndrome in full-term neonates. Chin Med J. 2010;123(19):2640-4.

9. Roth-Kleiner M, Wagner BP, Bachmann D, Pfenninger J. Respiratory distress syndrome in near-term babies after caesarean section. Swiss Med Wkly. 2003;133(19-20):283-8.

10. Hermansen CL, Lorah KN. Respiratory distress in the newborn. Am Fam Physician. 2007;76(7):987-94.

11. Lukkarinen HP, Laine J, Kaapa PO. Lung epithelial cells undergo apoptosis in neonatal respiratory distress syndrome. Pediatr Res. 2003;53(2):254-9. 